\title{
Erlotinib derivative inhibits hepatocellular carcinoma by targeting CIP2A to reactivate protein phosphatase $2 \mathrm{~A}$
}

\author{
H-C Yu ${ }^{1,2,11}$, M-H Hung ${ }^{3,4,11}$, Y-L Chen ${ }^{5,6,11}$, P-Y Chu ${ }^{7,8}$, C-Y Wang ${ }^{9}$, T-T Chao ${ }^{9}$, C-Y Liu ${ }^{10}$, C-W Shiau*,10 and K-F Chen ${ }^{\star, 1,2}$
}

Protein phosphatase 2A (PP2A) is a tumor suppressor, which is functionally defective in various cancers. Previously, we found that PP2A activity determined the anticancer effect of bortezomib and erlotinib in hepatocellular carcinoma (HCC) cells. Here, we tested a novel erlotinib derivative, TD52, in four HCC cell lines, PLC5, Huh-7, Hep3B and Sk-Hep1. Using MTT and flow cytometry, we showed that TD52 had more potent apoptotic effects than erlotinib in HCC cells. TD52-induced apoptosis was associated with dose- and time- dependent reactivation of PP2A and downregulation of cancerous inhibitor of protein phosphatase 2A (CIP2A) and p-Akt. Inhibition of PP2A or ectopic expression of CIP2A or Akt in PLC5 cells abolished the effects of TD52. Furthermore, we demonstrated that TD52 affected the binding of Elk-1 to the proximal promoter of the CIP2A gene, thus downregulating transcription of CIP2A. Importantly, TD52-induced tumor inhibition was associated with reactivation of PP2A and downregulation of CIP2A and p-Akt in vivo. In conclusion, we found that enhancement of PP2A activity by inhibition of CIP2A determines the apoptotic effect induced by TD52. Our findings disclose the therapeutic mechanism of this novel targeted agent, and suggest the therapeutic potential and feasibility of developing PP2A enhancers as a novel anticancer strategy.

Cell Death and Disease (2014) 5, e1359; doi:10.1038/cddis.2014.325; published online 31 July 2014

Hepatocellular carcinoma $(\mathrm{HCC})$ is the leading primary malignancy of the liver, the fifth most common cancer, and also the third leading cause of cancer-related death worldwide. $^{1,2}$ As a result of a lack of associated signs and symptoms at the early stage, HCC is often not discovered until the disease has reached an advanced stage when patients are not eligible for curative surgical resection. . $^{3,4}$ Furthermore, hepatocarcinogenesis is often associated with chronic inflammation related to various etiologies, including hepatitis $\mathrm{B}$ or $\mathrm{C}$ infection, alcohol or other hepatic toxin exposure and even non-alcoholic fatty disease. ${ }^{5,6}$ The complexity and heterogeneity of the disease contributes to intrinsic therapeutic resistance of HCC cells, which is echoed in the poor responsiveness to conventional chemotherapy and radiotherapy observed clinically. Sorafenib is the first and only FDA-approved targeted therapy for patients with advanced $\mathrm{HCC}^{3,4,6}$ It is a multi-targeted receptor tyrosine kinase inhibitor that promotes cancer cell death through inhibition of a range of kinases and receptors such as Raf-1, vascular endothelial growth factor receptor 1,2 and 3, and plateletderived growth factor receptor. ${ }^{7,8}$ Supported by the results of two large prospective phase III trials, ${ }^{9,10}$ sorafenib is currently used in advanced or metastatic HCC patients who are ineligible for surgical resection or liver transplantation. ${ }^{3}$ However, the treatment effects of sorafenib are disappointing; $<3 \%$ of patients have partial response to sorafenib and overall survival is only about 3 months longer than a placebo. ${ }^{9,10}$ Thus, development of novel targeted agents is urgently needed to improve treatment response and outcomes in HCC patients.

As $>80 \%$ of $\mathrm{HCC}$ develops in patients with pre-existing liver cirrhosis, ${ }^{3}$ and overexpression of epidermal growth factor (EGF) and EGF receptor (EGFR) are commonly observed in HCC tumors; ${ }^{11}$ development of agents targeting the EGFR signaling pathway has been one of the most thoroughly investigated strategies for HCC. Several different compounds targeting the EGFR pathway, including erlotinib and cetuximab have been examined in clinical trials. Erlotinib, a tyrosine kinase inhibitor, inhibits EGFR tyrosine kinase activity via competing with ATP to bind to the EGFR kinase domain. In two phase II clinical trials, modest disease control was observed in patients receiving erlotinib as a single agent. ${ }^{12,13}$ In the phase II trial reported by Zhu et al. ${ }^{14}$ with cetuximab, on the other hand, the antitumor response of cetuximab alone in treating HCC was poor; none of the studied patients responded $(n=30)$. Cetuximab is an immunoglobulin $\mathrm{G} 1$

\footnotetext{
${ }^{1}$ Department of Medical Research, National Taiwan University Hospital, Taipei, Taiwan; ${ }^{2}$ National Center of Excellence for Clinical Trial and Research, National Taiwan University Hospital, Taipei, Taiwan; ${ }^{3}$ Division of Hematology and Oncology, Department of Medicine, Taipei Veterans' General Hospital, Taipei, Taiwan; ${ }^{4}$ Program in Molecular Medicine, National Yang-Ming University and Academia Sinica, Taipei, Taiwan; ${ }^{5}$ Department of Surgery, Changhua Christian Hospital, Changhua, Taiwan; ${ }^{6}$ School of Medicine, Kaohsiung Medical University, Kaohsiung, Taiwan; ${ }^{7}$ Department of Pathology, St. Martin De Porres Hospital, Chiayi, Taiwan; ${ }^{8}$ School of Medicine, Fu-Jen Catholic University, New Taipei City, Taiwan; ${ }^{9}$ Medical Research Center, Cardinal Tien Hospital, Fu Jen Catholic University, New Taipei City, Taiwan and ${ }^{10}$ Institute of Biopharmaceutical Sciences, National Yang-Ming University, Taipei, Taiwan

*Corresponding authors: C-W Shiau, Institute of Biopharmaceutical Sciences, National Yang-Ming University, No. 155 Section 2, Li-Nong Street, Taipei, Taiwan. Tel: +886 2 28267930; Fax: +886 2 28250883; E-mail: cwshiau@ym.edu.tw

or K-F Chen, Department of Medical Research, National Taiwan University Hospital, No 7, Chung-Shan S Road, Taipei, Taiwan. Tel: +886 223123456 , ext: 63548 ; Fax: +886 2 23225329; E-mail: kfchen1970@ntu.edu.tw

${ }^{11}$ These authors contributed equally to this work.

Abbreviations: HCC, hepatocellular carcinoma; PP2A, protein phosphatase 2A; CIP2A, cancerous inhibitor of PP2A; PARP, poly (ADP-ribose) polymerase; DMEM, Dulbecco's modified Eagle's medium; FBS, fetal bovine serum

Received 17.4.14; revised 27.6.14; accepted 01.7.14; Edited by A Stephanou
} 
monoclonal antibody that binds specifically to EGFR and inhibits the downstream signaling pathway. ${ }^{15}$ The discrepant effects between these two treatments suggest that erlotinib has EGFR-independent antitumor effects on HCC cells.

In our previous work, we found that inhibition of cancerous inhibitor of protein phosphatase 2A (CIP2A) determines the apoptotic effects of erlotinib on HCC cells. ${ }^{16}$ CIP2A is a cellular inhibitor of the important tumor-suppressor protein, protein phosphatase 2A (PP2A). ${ }^{17}$ PP2A functions as a serine/threonine protein phosphatase that regulates several important oncogenic proteins such as c-Myc, ERK and Akt. ${ }^{18,19}$ When PP2A is inhibited by CIP2A, PP2A-mediated dephosphorylation of these oncoproteins is prohibited, thus promoting anchorage-independent cell growth and in vivo tumor formation. ${ }^{20}$ As we showed in our previous study, erlotinib enhanced the activity of PP2A by inhibiting CIP2A resulting in downregulation of $p$-Akt and cancer cell apoptosis. ${ }^{16}$ The anticancer mechanisms of bortezomib (a proteasome inhibitor) and rabdocoetsin B (an herbal extract of Rabdosia coetsa) have also been found to affect the same PP2A/CIP2A pathway. ${ }^{21-23}$ Moreover, expression of CIP2A was found in $>60 \%$ of human HCC samples, and the mRNA level of CIP2A detected in the tissue was correlated with clinical aggressiveness. ${ }^{24,25}$ Based on our findings and those of others, enhancing PP2A activity by targeting CIP2A may constitute a promising strategy for developing a novel HCC therapy.

In this study, we developed a novel erlotinib derivative, TD52, for the treatment of HCC. TD52 treatment in the micromolar range induced apoptosis of HCC cells through affecting CIP2A-dependent PP2A activation and p-Akt downregulation. Using MTT and sub-GI assay, TD52 was demonstrated to have enhanced anticancer efficacy when compared with erlotinib and sorafenib in HCC cells. TD52 enhanced PP2A activity and inhibited expression of CIP2A and p-Akt in a dose- and time-dependent manner. TD52-induced apoptosis was reduced by overexpressing CIP2A or Akt, and by inhibition of PP2A. Importantly, we found that transcription of CIP2A was inhibited by TD52 via interfering with the binding of Elk-1 to the promoter region of the CIP2A gene. Furthermore, we validated the response of TD52 in vivo. Using a xenograft nude mice model, we demonstrated that mice receiving TD52 treatment had greater reduction in tumor size than those receiving sorafenib or a control. Moreover, expression of CIP2A and p-Akt was significantly correlated in clinical HCC samples. Our results not only demonstrate the efficacy of TD52, but also suggest that enhancing PP2A by targeting CIP2A may be a promising anticancer strategy for HCC therapy.

\section{Results}

TD52, an erlotinib derivative, increases HCC cell apoptosis. TD52 is a derivative modified from erlotinib (Figure 1g). We used two strategies to compare the antitumor activities of TD52 and its mother compound, erlotinib, on HCC cells. First, we used MTT assay to evaluate cell viability after exposure to TD52 or erlotinib at the indicated doses for $48 \mathrm{~h}$. As shown in Figure 1a, TD52 caused greater reduction in cell viability than erlotinib in all the $\mathrm{HCC}$ cell lines tested including HA22T $\left(\mathrm{IC}_{50}=0.9 \mu \mathrm{mol} / \mathrm{I}\right)$, Hep3B $\quad\left(I_{50}=0.9 \mu \mathrm{mol} / \mathrm{I}\right), \quad$ PLC5 $\quad\left(I_{50}=0.8 \mu \mathrm{mol} / \mathrm{I}\right)$ and Sk-Hep1 $\left(\mathrm{IC}_{50}=1.2 \mu \mathrm{mol} / \mathrm{I}\right)$. To further evaluate the cell apoptosis induced by the treatments, all four cell lines were treated with TD52 and erlotinib at the indicated concentration for $24 \mathrm{~h}$ and the percentages of sub-G1 cells were determined by flow cytometry (Figure 1b). Results of subGI analysis echoed the findings observed in the MTT assay, that is, they showed that TD52 had more potent antitumor effects on HCC cells than erlotinib. To better characterize the antitumor properties of TD52, annexin-V/propidium iodide (PI) double-staining assay, western blot analysis, cell cycle analysis and DNA fragmentation assay were performed (Figures 1c-e, Supplementary Figures 1 and 2). As indicated by the results of western blotting, TD52 treatment caused the activation of caspase-9, caspase-3 and subsequent cleavage of poly (ADP-ribose) polymerase (PARP) in a dosedependent manner (Figure 1d). Furthermore, co-treatment of TD52 and z-VAD-fmk, the pan-caspase inhibitor, reduced the pro-apoptotic effects of TD52 (Figure 1f). Also, DNA fragmentation of cancer cells was induced by TD52 at relatively low concentration $(1 \mu \mathrm{mol} / \mathrm{l}, 24 \mathrm{~h}$; Figure 1e). In addition, by staining cells with annexin-V-FITC/PI, we demonstrated that the treatment of TD52 induced both apoptosis and necrosis of cancer cell (Figure 1c and Supplementary Figure 1). After $48 \mathrm{~h}$ incubation with TD52 at $2.5 \mu \mathrm{M}$ or higher doses, the extents of cancer cell death, included apoptotic and necrotic death, were $50 \%$ or more in the four different HCC cells (Figure 1c). Interestingly, we found that Hep3B cell was more sensitive to TD52-induced necrotic cell death, while apoptotic cell death was responsible for larger proportion of cell death in HA22T, PLC5 and Sk-Hep1 cells at the same dose range. Using cell cycle analysis, we found that the treatment of TD52 also significantly increased the percentage of S-phase arrest cancer cells at doses higher than $3 \mu \mathrm{M}$ (Supplementary Figure 2). Moreover, the effects of TD52 were independent of EGFR kinase inhibition (Figure 1h). Together, these results suggest that the erlotinib-derivative TD52 exhibits more potent antitumor activity than erlotinib, and that this activity is independent of EGFR kinase inhibition.

Enhancement of PP2A by inhibition of CIP2A determines the pro-apoptotic effect of TD52 treatment in HCC cells. In our previous study, we demonstrated that enhancement of PP2A activity by inhibition of CIP2A has a determining role in the antitumor effect of erlotinib on HCC cells. ${ }^{16}$ In light of our previous findings, we next investigated the molecular mechanism associated with TD52, with particular focus on the CIP2A-PP2A-p-Akt signaling pathway. As shown in Figures $2 a$ and b, TD52 downregulated the protein expression of CIP2A and p-Akt in a dose- and time-dependent manner. Furthermore, PP2A activity was enhanced by TD52 treatment (Figure 2c), while the expression level of PP2A-related subunits, PP2A-A, PP2A-B55 and PP2A-C subunits, were not affected (Figure $2 d$ ). From these results, we concluded that $\mathrm{PP} 2 \mathrm{~A}$ activity was enhanced by TD52 treatment through inhibition of expression of CIP2A that subsequently led to downregulation of $p-A K T$ and $\mathrm{HCC}$ cell apoptosis. 
a

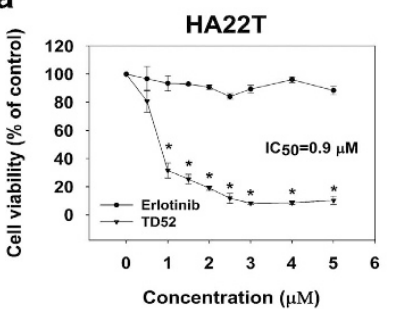

b

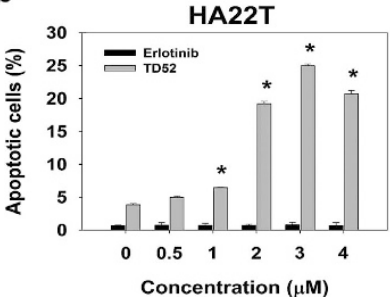

C
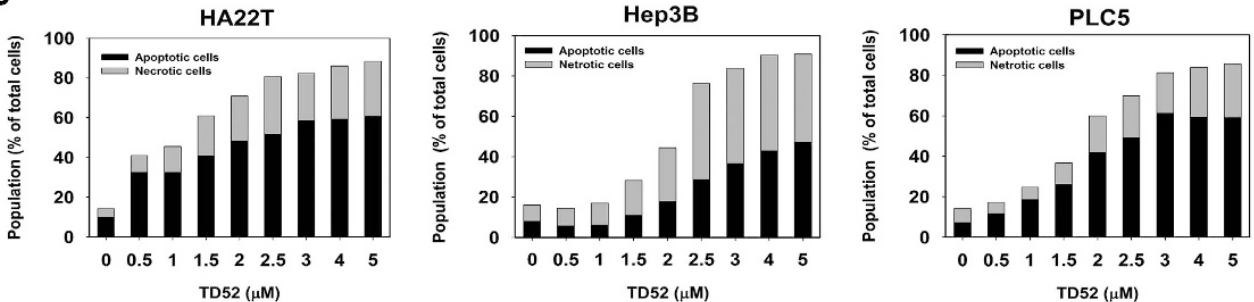

$\operatorname{TD} 52(\mu \mathrm{M})$
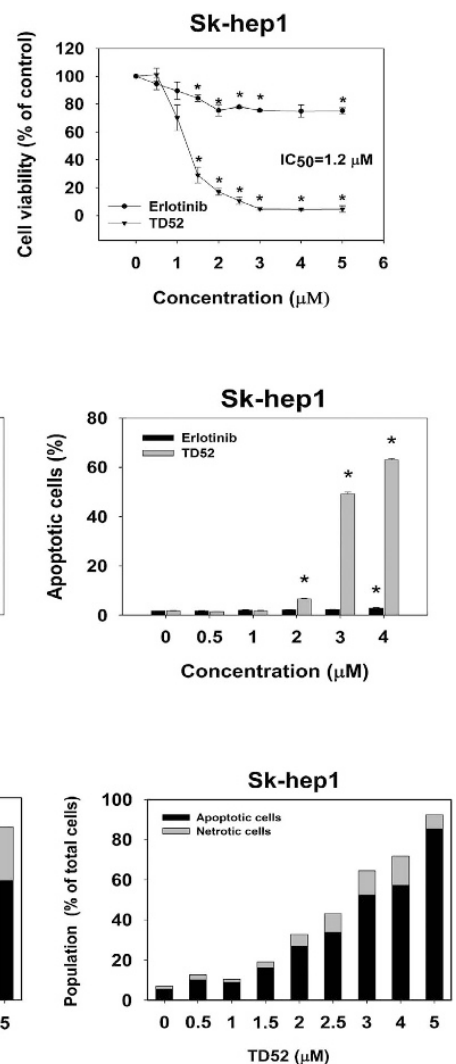

e
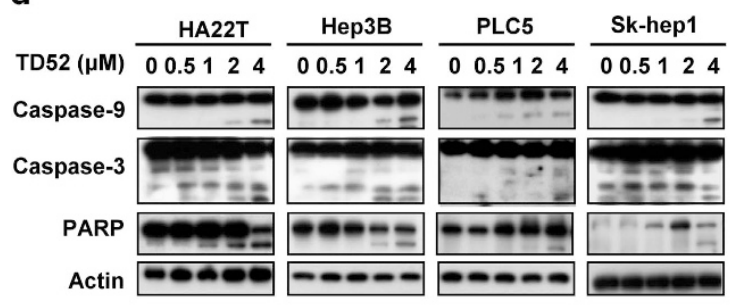

e
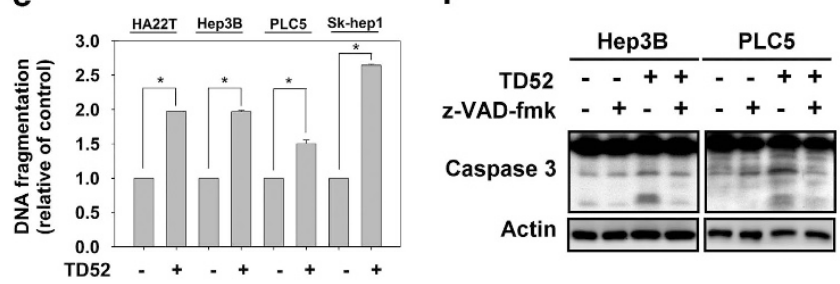

g

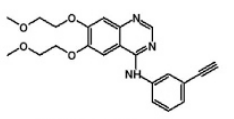

Erlotinib

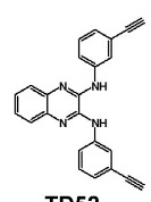

TD52 h

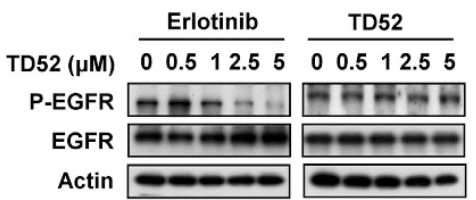

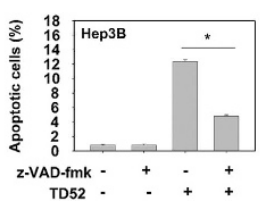

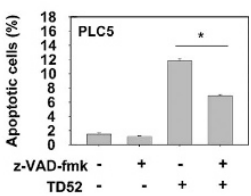

Figure 1 TD52, a derivative of erlotinib, showed a better pro-apoptotic effect of HCC cells than erlotinib. (a) Pro-apoptotic effects of erlotinib and TD52 in HCC cells. HCC cells were exposed to erlotinib and TD52 at the indicated concentrations for $48 \mathrm{~h}$, and then measured by MTT assay. IC 50 of TD52 in different cells were illustrated. Points, mean; bars, S.D. $(n=3)$. (b) Dose-dependent effect of TD52 and erlotinib on cell apoptosis in HCC cells. Percentage of apoptotic cells of HCC cells were measured by flow cytometry (sub-G1) after exposure to erlotinib and TD52 at indicated concentrations for $24 \mathrm{~h}$. Bar, mean; error bars, S.D. $(n=3)$. (c-e) Dose-escalation effect of TD52 in four different HCC cell lines. After incubation with TD52 at the indicated concentration in DMEM with $5 \%$ FBS for $24 \mathrm{~h}$ (for western blot and DNA fragmentation test) and $48 \mathrm{~h}$ (for annexin-V/PI double-staining assay), the HCC cells were harvested and analyzed by annexin-V/PI double-staining assay (c), western blot for the expression of caspases-3, caspases-9 and PARP (d), and DNA fragmentation test $(\mathbf{e}, n=6)$. Data of western blotting are representative of three independent experiments. Analysis of HCC cell condition in the annexin-V/PI double-staining assay was performed by flow cytometry and the proportion of apoptotic cells was determined as the sum of pro-apoptotic cell plus late apoptotic cell (annexin-V-FITC-positive cells). Result of flow cytometry was detailed in Supplementary Figure 1. $(n=3)$. (f) The pro-apoptotic effects induced by TD52 was

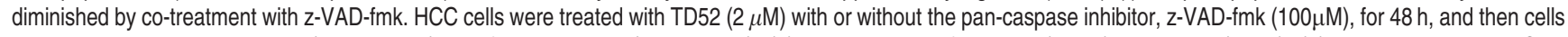
were analyzed by western blot (upper panel) and flow cytometry (lower panel). (g) The structure of erlotinib (upper) and TD52 (lower). (h) TD52 exhibit little EGFR phosphorylation activity. HCC cells treated with erlotinib or TD52 for $24 \mathrm{~h}$ and EGFR phosphorylation activity was determined by western blotting 
a

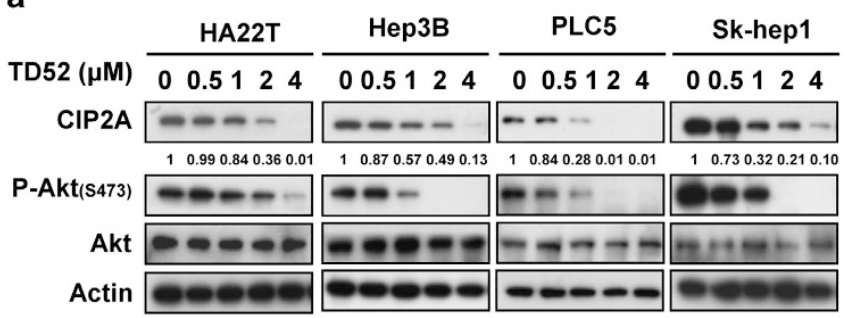

C

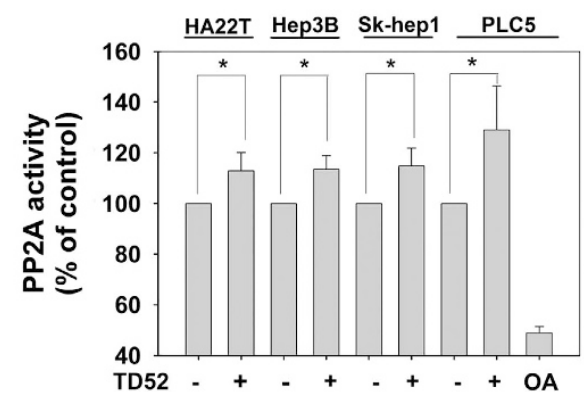

e

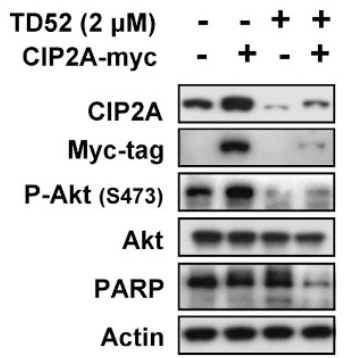

$\mathbf{g}$

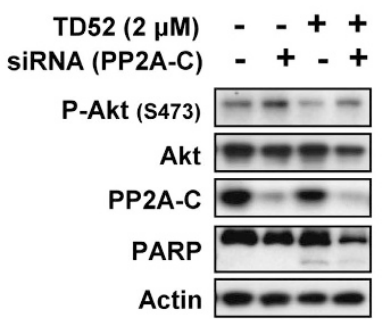

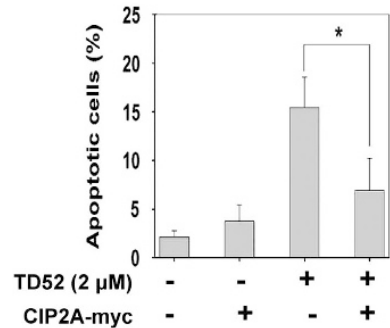

Figure 2 Targeting PP2A-dependent p-Akt downregulation by inhibition of CIP2A determined effects of TD52 on apoptosis in HCC cells. (a and $\mathbf{b}$ ) TD52 downregulated CIP2A protein expression in HCC cells in a dose-dependent and time-dependent manner. HCC cells were treated with TD52 at indicated concentration for $24 \mathrm{~h}(\mathrm{a})$ or at $1 \mu \mathrm{M}$ at indicated duration (b); cell lysates were subsequently collected for analysis of CIP2A, P-Akt, Akt protein expression by western blot. (c) PP2A activities in HCC cells were enhanced after treating with TD52. HCC cells were treated with TD52 at $1 \mu \mathrm{M}$ for $24 \mathrm{~h}$ and cell lysates were prepared for measuring PP2A phosphatase activity. Bar, mean; error bars, S.D. $(n=3)$. (d) The effects of TD52 on protein expression of PP2A. Cells were treated with TD52 at $1 \mu \mathrm{M}$ for $24 \mathrm{~h}$ and the expression of the subunits of PP2A were determined by western blot. (e) Ectopic expression of CIP2A-myc abolishes effects of TD52 on apoptosis in PLC5 cells. After transfecting PLC5 cells with CIP2A-myc for $48 \mathrm{~h}$, cells were treated with TD52 at $2 \mu \mathrm{M}$ for $24 \mathrm{~h}$ and analyzed by flow cytometry (sub-G1, right panel) and western blot (left panel). Bar, mean; error bars, S.D. ( $n=3$ ). (f) Co-treatment with OA, a PP2A inhibitor, reduced the effect of TD52 on P-Akt and apoptosis. PLC5 cells were treated with TD52 (2 $\mu$ M) and/or OA (100 nM) for $24 \mathrm{~h}$ and analyzed by western blot and flow cytometry. Bar, mean; error bars, S.D. $(n=3)$. $(\mathbf{g})$ Downregulating PP2A-C by siRNA diminished the pro-apoptotic effects of TD52 in PLC5 cells. Cells were first transfected with PP2A-C siRNA or mock for $48 \mathrm{~h}$ and treated with TD52 $(2 \mu \mathrm{M})$ for $24 \mathrm{~h}$. Cell apoptosis was analyzed by flow cytometry and expression of P-Akt, PP2A and PARP were analyzed by western blot. Bar, mean; error bars, S.D. $(n=3)$. (h) Ectopic expression of Akt1 abolished the effects of TD52 on apoptosis in PLC5 cells. After transfecting cells were with Akt-myc for $48 \mathrm{~h}$, cells were exposed to TD52 $(2 \mu \mathrm{M})$ for $24 \mathrm{~h}$ and analyzed by western blot and flow cytometry. Bar, mean; error bars, S.D. $(n=3)$

Target validation of the CIP2A/PP2A/pAkt pathway as the determinant molecular mechanism of TD52-induced HCC cell apoptosis. To confirm the role of the CIP2A/ PP2A/p-Akt pathway in mediating induction of apoptosis of
HCC cells by TD52, we generated PCL5 cells with ectopic overexpression of myc-tagged CIP2A by transient transfection (Figure 2e). Compared with wild-type cells, the expression level of p-AKT was upregulated in the CIP2A-overexpressing 
cells. Furthermore, using sub-Gl analysis, we found that the apoptotic effect of TD52 was significantly reduced in these CIP2A-overexpressing PLC5 cells. Next, we investigated the role of PP2A in mediating the effects of TD52 on HCC cells by two strategies, knockdown of PP2A by silencing RNA (siRNA), and co-treatment with a PP2A inhibitor, okadaic acid (OA) (Figures $2 f$ and g). When PLC5 cells were treated with $\mathrm{OA}$ at $100 \mathrm{nM}$, the expression level of $\mathrm{p}$-Akt was enhanced and TD52-induced HCC tumor cell apoptosis was reduced (Figure 2f). Similarly, when PP2A was knocked down by siRNA of PP2A, expression of $p$-Akt was increased and the antitumor effects of TD52 were reversed. In previous studies, we found that Akt serves as an important downstream effector of PP2A in erlotinib treatment. Therefore, we further generated Akt-overexpressing PLC5 cells by transient transfection and found that TD52-induced apoptosis of HCC cells was significantly reduced (Figure $2 \mathrm{~h}$ ). The results of PP2A inhibition and ectopic overexpression of CIP2A and Akt thus validated the critical role of the CIP2A/PP2A/p-Akt signaling pathway in mediating the effect of TD52 in HCC cells.

TD52 downregulates transcription of CIP2A via Elk-1 regulation in HCC cells. To further understand how TD52 affects the CIP2A/PP2A signaling pathway, we examined whether elimination (degradation) of CIP2A was affected by TD52 when translation was blocked by the protein synthesis inhibitor cycloheximide $(\mathrm{CHX})$. As shown in Figure $3 a$, the time needed for CIP2A protein degradation was not significantly affected by TD52 with or without $\mathrm{CHX}$, but the mRNA expression detected by RT-PCR was suppressed by TD52 treatment. As our findings suggested that TD52 inhibited transcription of CIP2A, we next examined whether the CIP2A promoter determined the mechanism of action. When the promoter of the CIP2A gene was linked to luciferase reporters, we found that TD52 suppressed the luciferase activity in a dose-dependent manner (Figure 3b, upper panel). In order to further identify which elements of the CIP2A gene promoter region were critical for the effects of TD52, serial PCR deletion clones were constructed in pGL4 luciferase vectors. As shown in Figure 3b, TD52 treatment did not affect luciferase activity in cells with the $-110 /-1$ construct. This finding suggests that the region between -110 and -150 contains the binding sites for CIP2A expression in PLC5 cells. Prior reports suggested that Elk-1 could bind to this region. Elk-1 regulated the expression levels of CIP2A in cervical and endometrial cancers together with another transcriptional factor, Ets $1 .{ }^{26} \mathrm{We}$, therefore, tested the role of Elk-1 in mediating the regulation of the CIP2A/PP2A signaling pathway in HCC cells. In treatmentnaive PLC5 cells, expression of Elk-1 and CIP2A could be detected by western blot; while the expression of Elk-1 was particularly dominant in the nuclear lysate, the expression of CIP2A was mostly identified in the cytoplasmic lysate. After TD52 treatment, however, the expression of both CIP2A and Elk-1 in PLC5 cells was significantly inhibited (Figure 3c). To further illustrate the interplay between Elk-1 and CIP2A, we used chromatin immunoprecipitation (ChIP) analysis and quantitative PCR to assess the direct association of Elk1 with the CIP2A promoter gene (Figure $3 d$ ). In treatment-naive cells, Elk-1 expression was detected in a cross-linked protein-DNA complex, which supported the direct binding of Elk-1 to the promoter regions of the CIP2A gene. Furthermore, when cells were exposed to TD52, the expression of Elk-1 was reduced in a dose-dependent manner. These results indicate that TD52 downregulates CIP2A by interfering with the binding between Elk-1 and the CIP2A promoter subsequently leading to decreased transcription of CIP2A. As CIP2A was inhibited, PP2A was activated, leading to dephosphorylation of Akt and cancer cell apoptosis. Moreover, ectopic overexpression of Elk-1 reduced TD52-induced downregulation of CIP2A and cancer cell apoptosis (Figure 3d, right panel).

In vivo antitumor effects of TD52 on a PLC5 xenograft tumor model. Next, to examine whether using TD52 to enhance PP2A activity has potential clinical relevance, we used a PLC5 xenograft mouse model to assess the effects of TD52 in vivo. To reflect the current clinical scenario, we chose sorafenib as one of the comparative treatment arms. Tumor-bearing mice were administered sorafenib $(10 \mathrm{mg} / \mathrm{kg} /$ day), TD52 (10 mg/kg/day) or DMSO (vehicle, as control). After 4 weeks of treatment, the tumor sizes of the mice receiving sorafenib and TD52 were smaller than those of the control arm. Furthermore, in a comparison with sorafenib, TD52 treatment demonstrated more potent inhibition of in vivo tumor growth and in vitro cell viability $(P<0.05$; Figures $4 \mathrm{a}$ and $\mathrm{d})$. Next, we examined the xenografted tumors taken from mice receiving TD52 and vehicle to confirm the molecular events in the tumor tissue. As shown in Figures $4 \mathrm{~b}$ and $\mathrm{c}$, TD52 enhanced PP2A activity and downregulated the expression levels of CIP2A and p-Akt in in vivo tumor samples, mirroring the molecular events found in vitro. In summary, TD52 was shown to interfere with binding between Elk-1 and the promoter of the CIP2A gene subsequently leading to downregulation of transcription of CIP2A and increased PP2A activity. When PP2A activity was enhanced by TD52, Akt was dephosphorylated, promoting HCC cell apoptosis (Figure 4e).

\section{Expression of CIP2A correlates with expression of p-Akt} in clinical liver tumor tissue from patients with HCC. To validate the clinical relevance of $p$-Akt and CIP2A, we analyzed tumor samples from 147 patients with HCCs and their clinical characteristics were summarized in Figure $4 \mathrm{~g}$. CIP2A was highly expressed in $55.5 \%$ of the tumor samples examined. Moreover, immunohistochemical staining for p-Akt showed that the intensity of nuclear expression of p-Akt correlated significantly with cytoplasmic staining for CIP2A $(P=0.019)$ and poor histological differentiation $(P=0.044$; Figures $4 \mathrm{f}-\mathrm{h})$.

\section{Discussion}

$\mathrm{HCC}$ is a major global health threat with $>700000$ new cases diagnosed annually worldwide. ${ }^{3}$ Despite improvement in antiHCC treatments over the past decade, survival of patients with the advanced disease is still dismal. ${ }^{9}$ Therefore, the development of effective anti-HCC treatment(s) to improve outcome in these patients is urgently needed. In this study, 
a
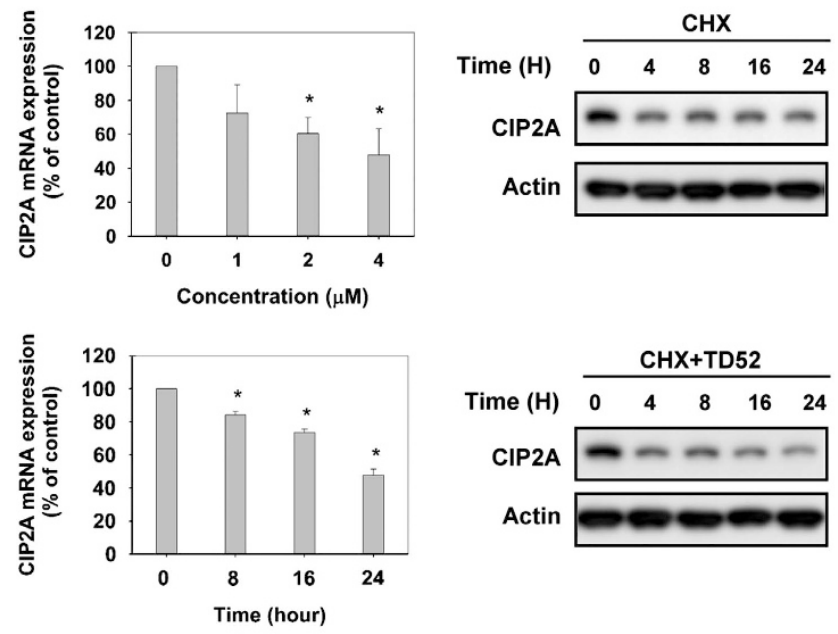

b
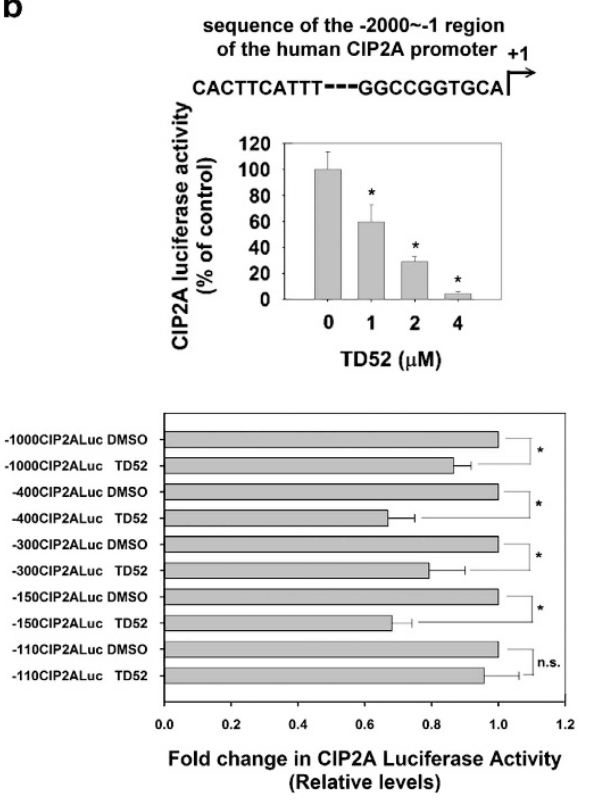

C

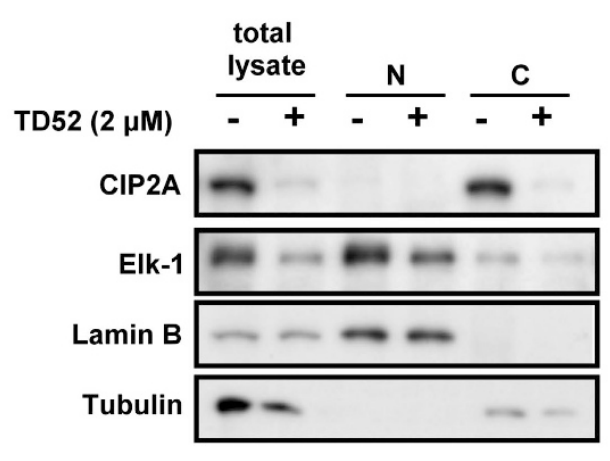

d

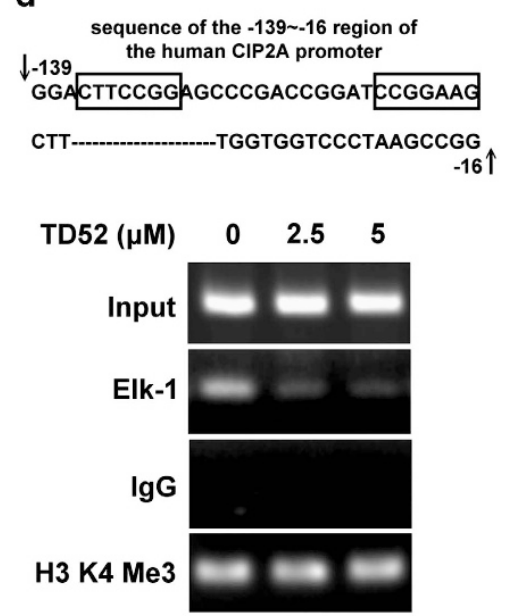

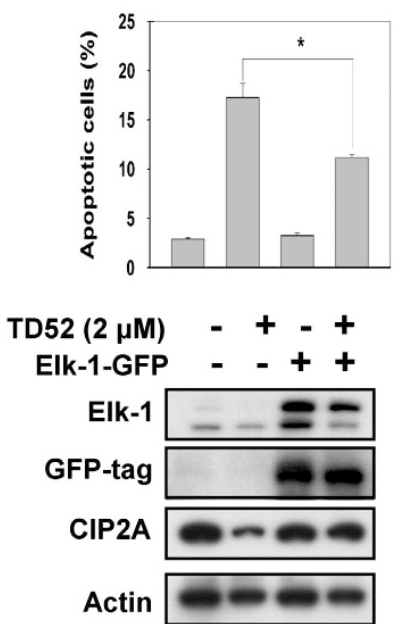

Figure 3 TD52 downregulated transcription of CIP2A via interfering Elk-1 function. (a) TD52 affected transcription of CIP2A in a dose- and time-dependent manner. Left panel, PLC5 cells were treated with D52 at indicated doses (upper panel) and time (lower panel); CIP2A mRNA was quantified by reverse transcription-PCR. Bar, mean; error bars, S.D. $(n=3)$ Right panel, after treating cells with $100 \mathrm{mg} / \mathrm{ml} \mathrm{CHX} \mathrm{in} \mathrm{the} \mathrm{presence} \mathrm{(lower)} \mathrm{or} \mathrm{absence} \mathrm{(upper)} \mathrm{of} \mathrm{TD52} \mathrm{for} \mathrm{the} \mathrm{indicated} \mathrm{length} \mathrm{of} \mathrm{time,} \mathrm{the} \mathrm{expression} \mathrm{of}$ CIP2A protein in whole-cell lysates was assessed by western blot. (b) Identification of the CIP2A proximal promoter region that was affected by TD52. CIP2A promoter activities at different doses of TD52 were first examined (upper panel). Promoters with five different length of deletion were constructed as detailed in the 'Materials and methods' section. Followed by transfecting with the mutant clone or the wide-type promoter for $24 \mathrm{~h}, \mathrm{PLC} 5$ cells were subsequently exposed to TD52 at $2 \mu \mathrm{M}$ and assayed for luciferase activity after another $24 \mathrm{~h}$. ( $n=3,{ }^{*} P<0.05$, Bar, mean; error bars, S.D. NS, nonsignificant). (c) TD52 affected the protein expression of Elk-1 and CIP2A in PLC5 cells. After exposure with TD52 at $2 \mu \mathrm{M}$ for $24 \mathrm{~h}, \mathrm{PLC5}$ cells were lysed and whole-cell extract, cytoplasmic and nuclear fractions were prepared. The expression of CIP2A and Elk-1 were analyzed by western blot. Tubulin and lamin B were used as loading control. (d) Inhibition of the binding of Elk-1 to the CIP2A promoter determined the effect of TD52 in PLC5 cells. Left panel, a ChIP assay was performed on TD52- or mock-treated PLC5 cells. The representative sequence of the CIP2A promoter (upper), $\square$ indicated the putative binding sites of Elk-1. ChIP assay was conducted to evaluate the DNA-binding ability of Elk-1 on the putative binding sites of CIP2A promoter region (lower). PLC5 cells were treated with TD52 at the indicated concentrations for $16 \mathrm{~h}$ and fixed for ChIP assay. The products were amplified by PCR and the result was presented by gel-electrophoresis. Right panel, ectopic expression of Elk-1 reduced the pro-apoptotic effects of TD52 in PLC5 cells. Cells were transfected with Elk-1-GFP for $48 \mathrm{~h}$ and exposed to TD52 $(2 \mu \mathrm{M})$ for $24 \mathrm{~h}$. Bar, mean; error bars, S.D. $(n=3)$

we introduced a new erlotinib derivative, TD52, and demonstrated its potent antitumor efficacy on HCC cells. Through affecting the CIP2A/PP2A/p-Akt signaling pathway, TD52 treatment in the micromolar range inhibited HCC cell growth (Figure 1). Compared with sorafenib (the current standard treatment for advanced HCC) and erlotinib, TD52 showed greater anti-HCC activity in vitro and in vivo. Furthermore, we found that the expression levels of CIP2A and p-Akt were highly correlated in clinical tumor samples. Our findings, therefore, illustrate the potential potency of TD52 as an HCC therapy, disclose its mechanism of action, and also support the rationale of developing agents to enhance PP2A activity in future drug development for HCC and/or other malignant diseases. 
a

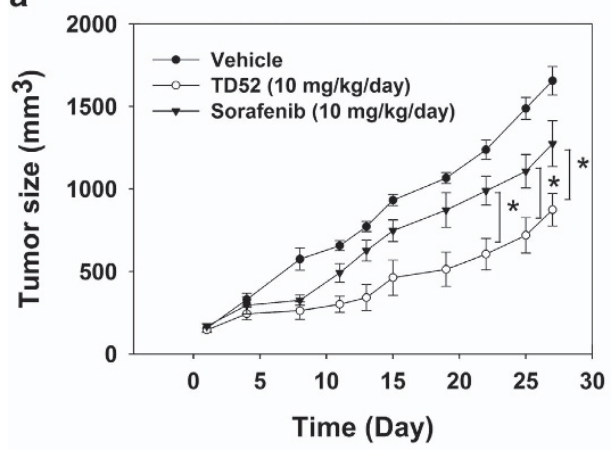

d

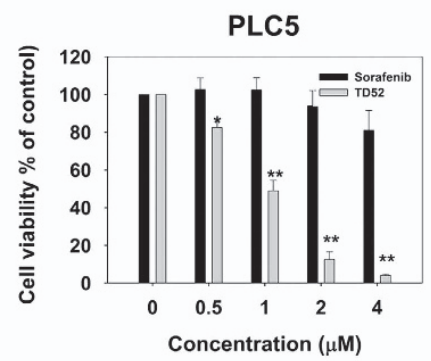

f
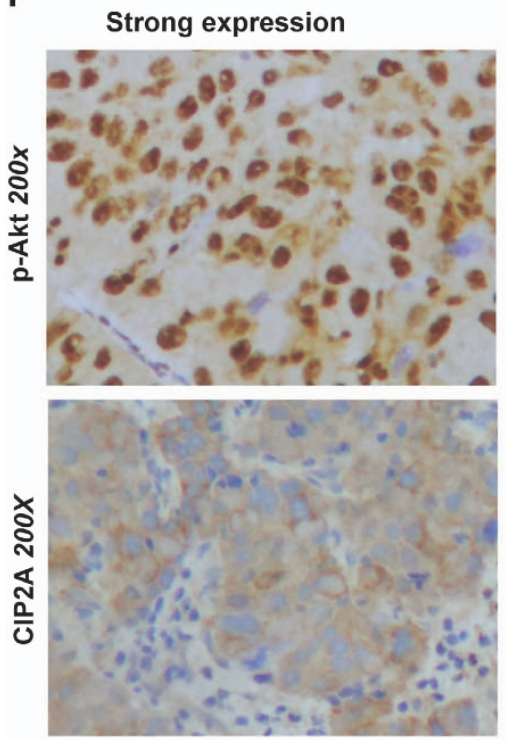

b
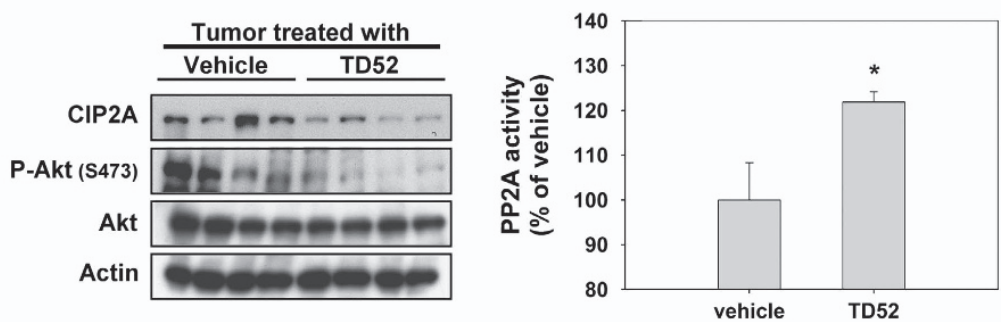

e

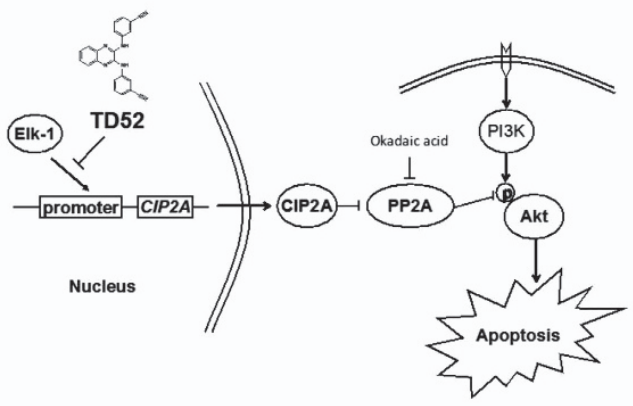

g
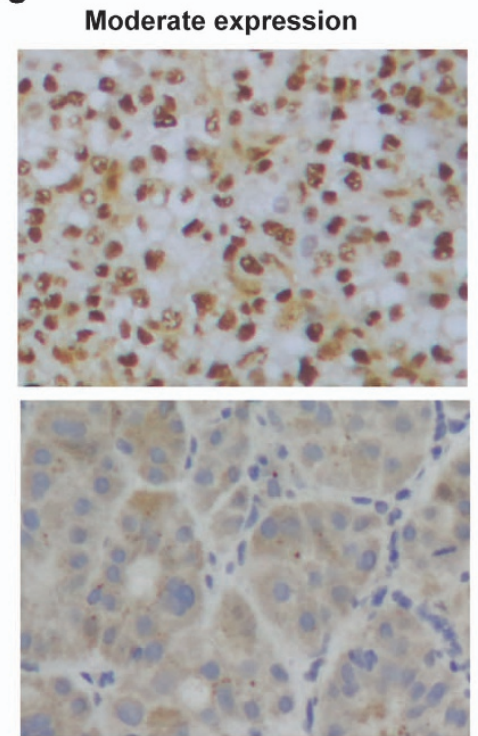

h
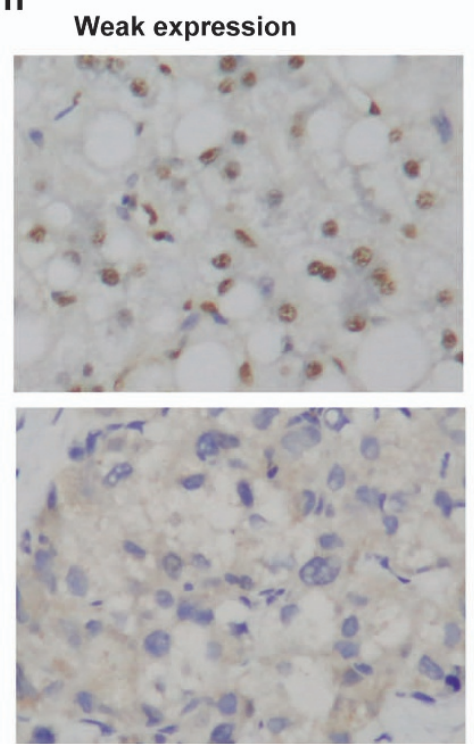

Figure 4 Validation of the CIP2A/PP2A/p-Akt in clinical HCC samples and in vivo PLC5 nude mice model. (a) The growth curves of PLC5 xenograft tumor in TD52-, sorafenib- and vehicle- treated nude mice. ${ }^{*} P<0.05$; Points, mean; bars, S.D. $(n=6)$. (b) The expression levels of CIP2A, P-Akt and Akt1 in PLC5 xenograft tumors were analyzed by western blot. (c) Analysis of PP2A activity of PLC5 xenograft tumor in TD52- and vehicle-treated nude mice. ${ }^{*} P<0.05$; Bar, mean; error bars, S.D. ( $n=3$ ). (d) Dose-dependent effects of sorafenib and TD52 on cell viability in PLC5 cells. PLC5 cells were treated with sorafenib and TD52 at indicated concentration for $48 \mathrm{~h}$ and cell viability was determined by MTT assay. Bar, mean; error bars, S.D. $(n=3)$. (e) Schema of the signaling pathways that explains pro-apoptotic effects of TD52 in HCC cells. (f-h) Expression analysis of CIP2A and p-Akt in clinical HCC tissues. Representative immunohistochemical patterns of strong (f, upper panel), moderate ( $\mathbf{g}$, upper panel) and weak (h, upper panel) p-Akt nuclear expression in HCC tissues. Although the representative immunohistochemical patterns of CIP2A of strong (f, lower panel), moderate $(\mathbf{g}$, lower panel) and weak (h, lower panel) cytoplasmic expression in cancer tissues. (Magnification, $\times 200)$

PP2A is a serine/threonine phosphatase that has a critical role in regulating various cellular processes, including protein synthesis, signaling transduction, cell cycle determination, apoptosis, metabolism and stress response. ${ }^{18,27,28}$ It has been suggested that PP2A functions as a tumor suppressor because OA, an inhibitor of PP2A, is a tumor promoter, ${ }^{29}$ and because loss of PP2A function has been identified in various malignant diseases such as cancer of the colon, liver, lung and breast. ${ }^{18,30}$ Furthermore, in the simian virus 40 -induced cell transformation model, activation of the oncoprotein RAS 
was not sufficient to cause cell transformation unless PP2A was simultaneously inhibited. ${ }^{27,31}$ All these data suggest that enhancing PP2A activity could be an effective approach for anticancer treatment. In this study, we showed that by inhibiting CIP2A (a cellular inhibitor of PP2A), activity of PP2A was significantly enhanced and expression of $\mathrm{p}$-Akt was downregulated in HCC cells (Figure 2) and xenografted nude mice (Figures $4 b$ and $c$ ). When CIP2A or Akt was overexpressed or PP2A was inhibited by OA or siRNA, TD52induced cell apoptosis was abolished (Figures $2 \mathrm{e}-\mathrm{h}$ ). Furthermore, ectopic expression of CIP2A upregulated the expression of $\mathrm{p}$-Akt, in agreement with the correlation between CIP2A and AKT immunohistochemical staining observed in clinical samples (Figures $4 f-h$ ). Our data validated the mechanism by which TD52-induced cancer cell apoptosis in HCC cells, that is, induction of cancer cell apoptosis by inhibiting CIP2A to reactivate PP2A and enhance PP2A-dependent p-Akt downregulation. In our previous work, we found that bortezomib, a proteasome inhibitor, promoted cancer cell death by affecting the same pathway in many malignant diseases. ${ }^{22,23,32}$ Moreover, two other structure-unrelated agents, rabdocoetsin and miR-375, have been reported to inhibit cancer cell growth by affecting the PP2A/CIP2A signaling pathway in lung and oral cancer, respectively. Other than $\mathrm{CIP} 2 \mathrm{~A}$, three different kinds of cellular inhibitor of PP2A have been described, namely, SET//2 $2{ }^{\mathrm{PP} 2 \mathrm{~A}}$, SETBP1 and PHAPI/pp32//2 ${ }^{\mathrm{PP} 1 \mathrm{~A}} .^{28} \mathrm{SET} / \mathrm{I}_{2}^{\mathrm{PP} 2 \mathrm{~A}}$ was reported to be associated with myeloid leukemogenesis and Wilms' tumors. Switzer et al. ${ }^{33}$ found that a novel apolipoprotein E-based peptide, COG112, could increase PP2A activity by inhibiting the interaction of SET with PP2AC in the breast cancer cell line, MDA-MB-23. In addition, an antiproliferative lectin, jacalin, was found to be able to counteract the interaction between PHAPI and PP2A and subsequently affect the ERK signaling pathway in colon cancer. ${ }^{34}$ These findings together with our current data confirm that PP2A is an important tumor suppressor and enhancing PP2A by targeting its inhibitors could be a feasible approach for anticancer treatment in many malignant diseases.

In this study, we further demonstrated that transcription of CIP2A was affected by TD52, and found that the binding of Elk-1 to the promoter of the CIP2A gene was affected by TD52. Elk-1 belongs to the ternary complex factor subfamily, which is a subgroup of the Ets family of transcription factors. ${ }^{35,36}$ Elk-1 participates in the regulation of many important genes, such as c-fos, ${ }^{37}$ plasminogen activator inhibitor-1, ${ }^{38} \mathrm{EZH} 2,{ }^{39} \mathrm{Mcl}-1,{ }^{40} \mathrm{PKC}$ alpha ${ }^{41}$ and cyclin D1, ${ }^{42}$ which are involved in the regulation of cell proliferation and apoptosis. Elk-1 is associated with tumorigenesis of many different malignant diseases, such as cancer of the breast, ${ }^{42,43}$ colon, $^{44}$ endometrium ${ }^{45}$ and HCC. ${ }^{26,41}$ In our study, we identified the binding site of Elk-1 in regulating transcription of CIP2A by using series of CIP2A promoterluciferase constructs (Figure $3 b$ ). As evidenced by ChIP assay, Elk-1 was bound to the proximal promoter of the CIP2A gene (Figure 3d). Furthermore, our data indicated that TD52 interfered with the function of Elk-1. As shown in Figures $3 \mathrm{c}$ and d, TD52 treatment results in dose-escalation inhibition of the binding between Elk-1 and the promoter of CIP2A gene. Moreover, when Elk-1 was overexpressed, the efficacy of
TD52 was reduced. These data indicate that Elk-1 affected transcription of CIP2A by direct interaction with its promoter, which was targeted by TD52 in HCC cells. In addition, Elk-1 has been found to affect the activation of the MAPK/ERK cascade induced by hepatitis $C$ virus core protein ${ }^{46,47}$ and the expression of PKC alpha. ${ }^{48}$ Whether these pathways are affected by TD52 is not yet known and more studies addressing these points will be needed in the future.

\section{Conclusion}

In this study, we introduced an erlotinib derivative, TD52, and demonstrated its novel therapeutic mechanism in HCC, that is, enhancement of PP2A-dependent p-Akt downregulation by inhibition of CIP2A. Our results suggest that designing agents to increase the activity of PP2A may be a feasible strategy for the development of novel HCC therapies. Further studies discussing the detailed molecular modification of the PP2A/CIP2A signaling pathway by TD52 and exploring its possible application in other malignant diseases are warranted.

\section{Materials and Methods}

Reagents and antibodies. Sorafenib (Nexavar) and erlotinib (Tarceva) were kindly provided by Bayer Pharmaceuticals (Pittsburgh, PA, USA) and Roche Pharmaceuticals (Basel, Switzerland) respectively. OA was purchased from Cayman Chemical (Ann Arbor, MI, USA) and z-VAD-fmk was obtained from Sigma (St. Louis, MO, USA). For in vitro studies, drugs at various concentrations were dissolved in dimethyl sulfoxide (DMSO), and added to cells in Dulbecco's modified Eagle's medium (DMEM) containing $5 \%$ fetal bovine serum (FBS).

For in vitro studies, the final DMSO concentration was $0.1 \%$ after addition to the medium. Antibodies for immunoblotting including anti-CIP2A, anti-Akt1, anti-PARP, anti-PP2A-C, anti-PP2A-A, anti-PP2A-B55 and anti-Elk-1 were purchased from Santa Cruz Biotechnology (San Diego, CA, USA). Other antibodies such, as anti-caspase-3 and anti-P-Akt (Ser473) were obtained from Cell Signaling (Danvers, MA, USA).

Cell culture and western blot analysis. The Sk-Hep1, PLC/PRF/5 (PLC5) and Hep3B cell lines were obtained from American Type Culture Collection (ATCC; Manassas, VA, USA). The Huh-7 HCC cell line was obtained from the Health Science Research Resources Bank (HSRRB; Osaka, Japan; JCRB0403). Cells were maintained in DMEM supplemented with $10 \%$ FBS in a $37^{\circ} \mathrm{C}$ humidified incubator in an atmosphere of $5 \% \mathrm{CO}_{2}$ in air. Lysates of $\mathrm{HCC}$ cells treated with drugs at the indicated concentrations for various time periods were prepared for immunoblotting of caspase-3, PARP, P-Akt, Akt, CIP2A and so on. Western blot analysis was performed as previously reported. ${ }^{22}$

Apoptosis analysis. The numbers of apoptotic cells after treatment with DMSO, sorafenib or TD52 were assessed by flow cytometry (sub-G1). Annexin-V/PI double-staining assay was used to determine numbers of both apoptotic and necrotic cells. For above tow assays, HCC cells were harvested after TD52 treatment and incubated with $\mathrm{PI}$ alone for sub-G1 assay and in combination with annexin-V-FITC. Analysis of cell composition was performed by flow cytometry. TD52-induced apoptotic cell death was assessed by western blot analysis of activated caspases and cleaved PARP, and cell death ELISA for cytoplasmic histone-associated DNA fragments (Roche, Indianapolis, IN, USA). The effect of co-treatment with TD52 and z-VAD-fmk, the caspase inhibitor, were assessed by western blot analysis and flow cytometry. All the apoptotic analysis was performed as previously reported. ${ }^{22}$

Cell cycle analysis. After incubating with DMSO or TD52 at indicated doses for $48 \mathrm{~h}$, the cell distribution was analyzed for the distribution of cell cycle. In brief, after treatment, four different HCC cell lines were harvested with Trypsin-EDTA and fixed with $75 \%$ alcohol overnight. Cells were washed off with $5 \mathrm{cc}$ phosphatebuffered saline (PBS) for two times and stained with PI (Sigma). The stained cells were analyzed by flow cytometry using DNA modeling software (ModFit LT4.0, Verity Software House, Topsham, ME, USA). The effects of TD19 on the distribution of cell-cycle phases were focused on non-apoptotic cells. 
Gene knockdown using siRNA. SMARTpool small interfering RNA (siRNA) reagents, including control (D-001810-10) and PP2A-C (L-003598-01) were purchased from Dharmacon (Chicago, IL, USA) and the experiments were performed as previously described. ${ }^{22}$ In brief, cells were first transfected with siRNA (final concentration, $100 \mathrm{nM}$ ) in six-well plates using the Dharma-FECT4 transfection reagent (Dharmacon) according to the manufacturer's instructions for $48 \mathrm{~h}$. Afterward, the medium was replaced and the cells were treated with TD52 $(2 \mu \mathrm{M}$ for $24 \mathrm{~h})$ and then harvested for western blot analysis and apoptosis analysis by flow cytometry.

Transient transfection. CIP2A cDNA (KIAA1524) and Elk-1 cDNA was purchased from Origene (RC219918 and RG208921; Rockville, MD, USA). Following transfection for $48 \mathrm{~h}$, cells were treated with TD52 for the indicated times and subsequently harvested for further analysis.

PP2A phosphatase activity. The protein phosphatase activity in each cell lysate was determined by measuring the generation of free phosphate from threonine phosphopeptide using the malachite green-phosphate complex assay as described by the manufacturer (Upstate Biotechnology, Lake Placid, NY, USA). In brief, HCC cell lysates were first prepared in a low-detergent lysis buffer. The phosphatase assay was carried out in a PP2A-specific reaction butter (Milipore Billerica, MA, USA) containing $750 \mu \mathrm{M}$ phosphopeptide substrate. After incubation for $10 \mathrm{~min}$ at $30^{\circ} \mathrm{C}$, the malachite dye was added and free phosphate was measured by optical density at $650 \mathrm{~nm}$. In order to avoid variation resulting from differences in the amount of immunoprecipitation protein between samples, the phosphatase activities were normalized to the amounts of PP2A immunoprecipitated, which were detected and quantified by immunoblot analysis for each treatment group.

Luciferase reporter constructs for the CIP2A promoter and 5' detection analysis. The upstream region of the CIP2A promoter containing exon 1 ( $-2000 \mathrm{bp}$ to $-1 \mathrm{bp}$ ) was amplified by PCR from the genomic DNA of PLC5 cells according to a previous study and cloned into the reporter vector, Firefly vector (pGL4.17, Promega, Madison, WI, USA) by Kpnl and Bgll restriction sites. PCR amplified promoter regions $-1000 /-1,-400 /-1,-300 /-1$, $-150 /-1,-110 /-1$, were cloned into the Kpnl and Bgll restriction sites of the pGL4-basic vector. The nucleotide sequence of the clones was verified by sequencing.

ChIP assay. ChIP kit was purchased from Novus Biologicals (NBP1-71709; Littleton, CO, USA). ChIP was performed using $1 \times 10^{7}$ PLC5 cells, which were treated with TD52 for $16 \mathrm{~h}$, followed by $37 \%$ formaldehyde (Sigma, F1635) at $1 \%$ final concentration and $\mathrm{v} / \mathrm{v}$ for $10 \mathrm{~min}$ at room temperature to cross-link proteins to DNA. After cross-linking, the cells were washed twice with $1 \mathrm{x}$ ice-cold PBS containing protease inhibitor cocktail. The cells were collected and centrifuged at $800 \times g$ for $5 \mathrm{~min}$, resuspended in $400 \mu \mathrm{l}$ of lysis buffer with protease inhibitor cocktail. The cells were then sonicated for six pulses, $50 \%$ output for $15 \mathrm{~s}$ at each pulse, with a 60 -s ice rest in between pulses. The cell lysate was centrifuged at $12500 \times g$ for 5 min at $4{ }^{\circ} \mathrm{C}$. Immunoprecipitation was performed by adding Elk1 or rabbit lgG antibodies as the negative control. The immunocomplex was precipitated by incubation with $25 \mu$ l of protein $A / G$ magnetic beads for $1 \mathrm{~h}$ at $4{ }^{\circ} \mathrm{C}$. The protein-DNA complex was eluted using $200 \mu \mathrm{l}$ of elution buffer from the beads. Cross-linking of protein-DNA was reversed by adding $8 \mu \mathrm{l}$ of $5 \mathrm{M} \mathrm{NaCl}$ at $95^{\circ} \mathrm{C}$ for $15 \mathrm{~min}$. The DNA was purified using spin columns and $2 \mu \mathrm{l}$ of the DNA was used in the semi-PCR reaction for amplification of the CIP2A promoter region $(-139 /-16 b p)$

Xenograft tumor growth. Male NCr athymic nude mice (5-7 weeks of age) were obtained from the National Laboratory Animal Center (Taipei, Taiwan). All experimental procedures using these mice were performed in accordance with protocols approved by the Institutional Laboratory Animal Care and Use Committee of National Taiwan University. Each mouse was inoculated subcutaneously in the dorsal flank with $1 \times 10^{6}$ PLC5 cells suspended in $0.1 \mathrm{ml}$ of serum-free medium containing $50 \%$ Matrigel (BD Biosciences, Bedford, MA USA). When tumors reached $100-150 \mathrm{~mm}^{3}$, mice were treated with sorafenib, TD52, or vehicle (control) at $10 \mathrm{mg} / \mathrm{kg} /$ day daily by oral gavage for 4 weeks.

Immunohistochemical staining. Paraffin-embedded HCC tissue sections $(4-\mu \mathrm{m})$ on poly-1-lysine-coated slides were deparaffinized and rinsed with $10 \mathrm{mM}$
Tris-HCl ( $\mathrm{pH}$ 7.4) and $150 \mathrm{mM}$ sodium chloride. Peroxidase was quenched with methanol and $3 \%$ hydrogen peroxide. Slides were then placed in $10 \mathrm{mM}$ citrate buffer $(\mathrm{pH} 6.0)$ at $100{ }^{\circ} \mathrm{C}$ for $20 \mathrm{~min}$ in a pressurized heating chamber. After incubation with 1:200 dilution of $\mathrm{p}-\mathrm{Akt1} 1 / 2 / 3$ (Thr 308)-R antibody (ab8805, Abcam, Cambridge, UK) and with 1:100 dilution of CIP2A antibody (ab84547, Abcam) for $1 \mathrm{~h}$ at room temperature, slides were thoroughly washed three times with PBS. Bound antibodies were detected using the EnVision Detection Systems Peroxidase/DAB, Rabbit/Mouse kit (Dako, Glostrup, Denmark). The slides were then counterstained with hematoxylin. Paraffin-embedded sections of mouse kidney tissue and human colon carcinoma were used as positive controls for p-Akt1/2/3 and CIP-2A, respectively, as described in the datasheet from the manufacturer. Negative controls had the primary antibody replaced by PBS. The expression of $p$-Akt1/2/3 and CIP-2A was assessed semiquantitatively based on the intensity of staining by a board certified pathologist. The intensity of staining was scored as negative, weak, moderate and strong.

This study was approved by the ethics committee of the Institutional Review Board of Changhua Christian Hospital. All informed consents from sample donors were in accordance with the Declaration of Helsinki and were obtained at the time of their donation.

Statistical analysis. Tumor growth data points are reported as mean tumor volume \pm S.E. and compared by independent samples $t$-test. Characteristics of clinical samples were compared by $\chi^{2}$-test. A $P$-value $<0.05$ was regarded as statistically significant on the two-tailed tests. All statistical analysis was computed using SPSS for Windows software (version 17.0; SPSS, Inc., Chicago, IL, USA).

\section{Conflict of Interest}

The authors declare no conflict of interest.

Acknowledgements. This study is supported by grant NSC102-2325-B-002031 (to K-F Chen) from the National Science Council, Taiwan.

1. Altekruse SF, McGlynn KA, Reichman ME. Hepatocellular carcinoma incidence, mortality, and survival trends in the United States from 1975 to 2005. J Clin Oncol 2009; 27 1485-1491.

2. Parkin DM, Bray F, Ferlay J, Pisani P. Estimating the world cancer burden: Globocan 2000. Int J Cancer 2001; 94: 153-156.

3. Forner A, Llovet JM, Bruix J. Hepatocellular carcinoma. Lancet 2012; 379: 1245-1255.

4. Bruix J, Sherman M. Management of hepatocellular carcinoma. Hepatology (Baltimore, MD) 2005 ; 42: 1208-1236

5. Ding J, Wang H. Multiple interactive factors in hepatocarcinogenesis. Cancer Lett 2014; 346: 17-23.

6. El-Serag HB. Hepatocellular carcinoma. N Engl J Med 2011; 365: 1118-1127.

7. Liu L, Cao Y, Chen C, Zhang X, McNabola A, Wilkie D et al. Sorafenib blocks the RAF/MEK/ERK pathway, inhibits tumor angiogenesis, and induces tumor cell apoptosis in hepatocellular carcinoma model PLC/PRF/5. Cancer Res 2006; 66: 11851-11858.

8. Adnane L, Trail PA, Taylor I, Wilhelm SM. Sorafenib (BAY 43-9006, Nexavar), a dualaction inhibitor that targets RAF/MEK/ERK pathway in tumor cells and tyrosine kinases VEGFR/PDGFR in tumor vasculature. Methods Enzymol 2006; 407: 597-612.

9. Llovet JM, Ricci S, Mazzaferro V, Hilgard P, Gane E, Blanc JF et al. Sorafenib in advanced hepatocellular carcinoma. N Engl J Med 2008; 359: 378-390.

10. Cheng AL, Kang YK, Chen Z, Tsao CJ, Qin S, Kim JS et al. Efficacy and safety of sorafenib in patients in the Asia-Pacific region with advanced hepatocellular carcinoma: a phase III randomised, double-blind, placebo-controlled trial. Lancet Oncol 2009; 10: 25-34.

11. Baek HJ, Lim SC, Kitisin K, Jogunoori W, Tang Y, Marshall MB et al. Hepatocellular cancer arises from loss of transforming growth factor beta signaling adaptor protein embryonic liver fodrin through abnormal angiogenesis. Hepatology (Baltimore, MD) 2008; 48: 1128-1137.

12. Thomas MB, Chadha R, Glover K, Wang X, Morris J, Brown T et al. Phase 2 study of erlotinib in patients with unresectable hepatocellular carcinoma. Cancer 2007; 110: 1059-1067.

13. Philip PA, Mahoney MR, Allmer C, Thomas J, Pitot HC, Kim G et al. Phase II study of erlotinib (OSI-774) in patients with advanced hepatocellular cancer. J Clin Oncol 2005; 23: 6657-6663.

14. Zhu AX, Stuart K, Blaszkowsky LS, Muzikansky A, Reitberg DP, Clark JW et al. Phase 2 study of cetuximab in patients with advanced hepatocellular carcinoma. Cancer 2007; 110: 581-589.

15. Prewett M, Rothman M, Waksal H, Feldman M, Bander NH, Hicklin DJ. Mouse-human chimeric anti-epidermal growth factor receptor antibody C225 inhibits the growth of human renal cell carcinoma xenografts in nude mice. Clin Cancer Res 1998; 4: 2957-2966. 
16. Yu HC, Chen HJ, Chang YL, Liu CY, Shiau CW, Cheng AL et al. Inhibition of CIP2A determines erlotinib-induced apoptosis in hepatocellular carcinoma. Biochem Pharmacol 2013; 85: 356-366.

17. Junttila MR, Puustinen $P$, Niemela $M$, Ahola R, Arnold $H$, Böttzauw T et al. CIP2A inhibits PP2A in human malignancies. Cell 2007; 130: 51-62.

18. Mumby M. PP2A: unveiling a reluctant tumor suppressor. Cell 2007; 130: 21-24.

19. Janssens V, Goris J. Protein phosphatase $2 A$ : a highly regulated family of serine/threonine phosphatases implicated in cell growth and signalling. Biochem J 2001; 353: 417-439.

20. Junttila MR, Li SP, Westermarck J. Phosphatase-mediated crosstalk between MAPK signaling pathways in the regulation of cell survival. FASEB J 2008; 22: 954-965.

21. Ma L, Wen ZS, Liu Z, Hu Z, Ma J, Chen XQ et al. Overexpression and small moleculetriggered downregulation of CIP2A in lung cancer. PloS One 2011; 6: e20159.

22. Chen KF, Liu CY, Lin YC, Yu HC, Liu TH, Hou DR et al. CIP2A mediates effects of bortezomib on phospho-Akt and apoptosis in hepatocellular carcinoma cells. Oncogene 2010; 29: 6257-6266.

23. Tseng LM, Liu CY, Chang KC, Chu PY, Shiau CW, Chen KF. CIP2A is a target of bortezomib in human triple negative breast cancer cells. Breast Cancer Res 2012; 14: R68.

24. He H, Wu G, Li W, Cao Y, Liu Y. CIP2A is highly expressed in hepatocellular carcinoma and predicts poor prognosis. Diagn Mol Pathol 2012; 21: 143-149.

25. Huang P, Qiu J, You J, Hong J, Li B, Zhou K et al. Expression and prognostic significance of CIP2A mRNA in hepatocellular carcinoma and nontumoral liver tissues. Biomarkers 2012; 17: 422-429.

26. Pallai R, Bhaskar A, Sodi V, Rice LM. Ets1 and Elk1 transcription factors regulate cancerous inhibitor of protein phosphatase $2 \mathrm{~A}$ expression in cervical and endometrial carcinoma cells. Transcription 2012; 3: 323-335.

27. Westermarck J, Hahn WC. Multiple pathways regulated by the tumor suppressor PP2A in transformation. Trends Mol Med 2008; 14: 152-160.

28. Chen W, Wang Z, Jiang C, Ding Y. PP2A-mediated anticancer therapy. Gastroenterol Res Pract 2013; 2013: 675429

29. Fujiki $\mathrm{H}$, Suganuma $\mathrm{M}$. Unique features of the okadaic acid activity class of tumor promoters. J Cancer Res Clin Oncol 1999; 125: 150-155.

30. Seshacharyulu P, Pandey P, Datta K, Batra SK. Phosphatase: PP2A structural importance, regulation and its aberrant expression in cancer. Cancer Lett 2013; 335: 9-18.

31. Khanna A, Pimanda JE, Westermarck J. Cancerous inhibitor of protein phosphatase $2 A$, an emerging human oncoprotein and a potential cancer therapy target. Cancer Res 2013; 73 6548-6553.

32. Liu CY, Shiau CW, Kuo HY, Huang HP, Chen MH, Tzeng CH et al. Cancerous inhibitor of protein phosphatase $2 \mathrm{~A}$ determines bortezomib-induced apoptosis in leukemia cells. Haematologica 2013; 98: 729-738.

33. Switzer CH, Cheng RY, Vitek TM, Christensen DJ, Wink DA, Vitek MP. Targeting SET/I(2)PP2A oncoprotein functions as a multi-pathway strategy for cancer therapy Oncogene 2011; 30: 2504-2513.

34. Yu LG, Packman LC, Weldon M, Hamlett J, Rhodes JM. Protein phosphatase 2A, a negative regulator of the ERK signaling pathway, is activated by tyrosine phosphorylation of putative HLA class II-associated protein I (PHAPI)/pp32 in response to the antiproliferative lectin, jacalin. J Biol Chem 2004; 279: 41377-41383.

35. Hipskind RA, Rao VN, Mueller CG, Reddy ES, Nordheim A. Ets-related protein Elk-1 is homologous to the c-fos regulatory factor p62TCF. Nature 1991; 354: 531-534.

36. Rao VN, Reddy ES. A divergent ets-related protein, elk-1, recognizes similar c-ets-1 proto-oncogene target sequences and acts as a transcriptional activator. Oncogene 1992 7: $65-70$.
37. Hill CS, Treisman R. Transcriptional regulation by extracellular signals: mechanisms and specificity. Cell 1995; 80: 199-211.

38. Wyrzykowska P, Stalinska K, Wawro M, Kochan J, Kasza A. Epidermal growth factor regulates PAI-1 expression via activation of the transcription factor Elk-1. Biochimica et Biophysica Acta 2010; 1799: 616-621.

39. Yeh HY, Cheng SW, Lin YC, Yeh CY, Lin SF, Soo VW. Identifying significant genetic regulatory networks in the prostate cancer from microarray data based on transcription factor analysis and conditional independency. BMC Med Genomics 2009; 2: 70.

40. Goncharenko-Khaider N, Matte I, Lane D, Rancourt C, Piche A. Ovarian cancer ascites increase Mcl-1 expression in tumor cells through ERK1/2-Elk-1 signaling to attenuate TRAlL-induced apoptosis. Mol Cancer 2012; 11: 84.

41. Ying TH, Hsieh YH, Hsieh YS, Liu JY. Antisense oligonucleotide Elk-1 suppresses the tumorigenicity of human hepatocellular carcinoma cells. Cell Biol Int 2008; 32: 210-216.

42. Laliotis A, Vrekoussis T, Kafousi M, Sanidas E, Askoxilakis J, Melissas J et al. Immunohistochemical study of pElk-1 expression in human breast cancer: association with breast cancer biologic profile and clinicopathologic features. Breast (Edinburgh, Scotland) 2013; 22: 89-95.

43. Zhang X, Zhang B, Gao J, Wang X, Liu Z. Regulation of the microRNA 200b (miRNA-200b) by transcriptional regulators PEA3 and ELK-1 protein affects expression of Pin1 protein to control anoikis. J Biol Chem 2013; 288: 32742-32752.

44. Jin Q, Liu G, Domeier PP, Ding W, Mulder KM. Decreased tumor progression and invasion by a novel anti-cell motility target for human colorectal carcinoma cells. PloS One 2013; 8: e66439.

45. Sun NK, Huang SL, Chang TC, Chao CC. Sorafenib induces endometrial carcinoma apoptosis by inhibiting Elk-1-dependent Mcl-1 transcription and inducing Akt/GSK3betadependent protein degradation. J Cell Biochem 2013; 114: 1819-1831.

46. Hayashi J, Aoki H, Kajino K, Moriyama M, Arakawa Y, Hino O. Hepatitis C virus core protein activates the MAPK/ERK cascade synergistically with tumor promoter TPA, but not with epidermal growth factor or transforming growth factor alpha. Hepatology (Baltimore MD) 2000; 32: 958-961.

47. Giambartolomei S, Covone F, Levrero M, Balsano C. Sustained activation of the Raf/MEK/ Erk pathway in response to EGF in stable cell lines expressing the Hepatitis C Virus (HCV) core protein. Oncogene 2001; 20: 2606-2610.

48. Hsieh YH, Wu TT, Tsai JH, Huang CY, Hsieh YS, Liu JY. PKCalpha expression regulated by Elk-1 and MZF-1 in human HCC cells. Biochem Biophys Res Commun 2006; 339: 217-225.

(c) (i) $(\Theta$ Cell Death and Disease is an open-access journal published by Nature Publishing Group. This work is licensed under a Creative Commons Attribution-NonCommercialNoDerivs 3.0 Unported License. The images or other third party material in this article are included in the article's Creative Commons license, unless indicated otherwise in the credit line; if the material is not included under the Creative Commons license, users will need to obtain permission from the license holder to reproduce the material. To view a copy of this license, visit http://creativecommons.org/licenses/ by-nc-nd/3.0/ 